\title{
Trends in self-reported past alcoholic beverage consumption and ethanol intake from 1950 to 1995 observed in eight European countries participating in the European Investigation into Cancer and Nutrition (EPIC)
}

\author{
K Klipstein-Grobusch ${ }^{1, *}$, N Slimani ${ }^{2}$, V Krogh $^{3}, \mathrm{U} \mathrm{Keil}^{4}, \mathrm{H}^{\text {Boeing }}{ }^{1}, \mathrm{~K}$ Overvad $^{5}$,
} A Tiønneland ${ }^{6}$, F Clavel-Chapelon ${ }^{7}$, A Thiébaut ${ }^{7}$, J Linseisen $^{8}$, MB Schulze ${ }^{1}$, P Lagiou9, A Papadimitrou ${ }^{9}$, C Saieva $^{10}$, F Veglia ${ }^{11}$, HB Bueno-de-Mesquita ${ }^{12}$, PHM Peeters ${ }^{13}$, M Kumle ${ }^{14}$, M Brustad $^{14}$, C Martínez García ${ }^{15}$, A Barricarte ${ }^{16}$, G Berglund ${ }^{17}$, L Weinehall $^{18}$, A Mulligan ${ }^{19}, \mathrm{~N}$ Allen $^{20}$, P Ferrari $^{2}$ and E Riboli ${ }^{2}$

'Department of Epidemiology, German Institute of Human Nutrition, Arthur Scheunert-Allee 114-1 16, D-14558 Potsdam-Rehbrücke, Germany: ${ }^{2}$ Unit of Nutrition and Cancer, International Agency for Cancer Research, Lyon, France: ${ }^{3}$ Epidemiology Unit, National Cancer Institute, Milan, Italy: ${ }^{4}$ Department of Epidemiology and Social Medicine, University of Münster, Germany: ${ }^{5}$ Department of Epidemiology, University of Aarhus, Denmark: ${ }^{6}$ Institute of Cancer Epidemiology, Danish Cancer Society, Copenhagen, Denmark: ${ }^{7}$ INSERM, E3N-EPIC Group, Institute Gustave Roussy, Villejuif, France: ${ }^{8}$ Department of Clinical Epidemiology, German Cancer Research Centre, Heidelberg, Germany: 'Department of Hygiene and Epidemiology, School of Medicine, University of Athens, Greece: ${ }^{10}$ Molecular and Nutritional Epidemiology Unit, CSPO, Scientific Institute of Tuscany, Florence, Italy: ${ }^{11}$ Institute for Scientific Interchange Foundation, Turin, Italy: ${ }^{12}$ Department for Chronic Disease Epidemiology, National Institute for Public Health and Environmental Protection, Bilthoven, The Netherlands: ${ }^{13} \mathrm{Julius}$ Center for General Practice and Patient Oriented Research, University of Utrecht, The Netherlands: ${ }^{14}$ Institute of Community Medicine, University of Tromsø, Norway: ${ }^{15}$ Andalusian School of Public Health, Granada, Spain: ${ }^{16}$ Department of Epidemiology, Institute of Public Health of Navarra, Spain: ${ }^{17}$ Department of Medicine, Lund University, Malmö, Sweden: ${ }^{18}$ Epidemiology, Public Health and Clinical Medicine, Umeå University, Sweden: ${ }^{19}$ Department of Public Health and Primary Care, University of Cambridge, UK: ${ }^{20}$ Cancer Research UK, Cancer Epidemiology Unit, University of Oxford, UK

\begin{abstract}
Objective: To describe the trends of self-reported past consumption of alcoholic beverages and ethanol intake from 1950 to 1995 within the European Prospective Investigation into Cancer and Nutrition (EPIC).

Design: Data on consumption of beer/cider, wine and liqueur/spirits were obtained retrospectively at age 20,30 and 40 years to calculate average consumption and ethanol intake for the time periods 1950-1975 (at age 20), 1960-1985 (at age 30) and 1970-1995 (at age 40). Regression analysis was conducted with the time period data to assess trends in past alcoholic beverage consumption and ethanol intake with time. Setting: The EPIC project.

Subjects: In total, 392064 EPIC participants (275249 women and 116815 men) from 21 study centres in eight European countries.

Results: Generally, increases in beer/cider consumption were observed for most EPIC centres for 1950-1975, 1960-1985 and 1970-1995. Trends in wine consumption differed according to geographical location: downward trends with time were observed for men in southern European EPIC centres, upward trends for those in middle/northern European study centres. For women, similar but less pronounced trends were observed. Because wine consumption was the major contributor to ethanol intake for both men and women in most study centres, time trends for ethanol intake showed a similar geographical pattern to that of wine consumption.

Conclusion: The different trends in alcoholic beverage consumption and ethanol intake suggest that information depicting lifetime history of ethanol intake should be included in analyses of the relationship between ethanol and chronic diseases, particularly in multi-centre studies such as EPIC.
\end{abstract}

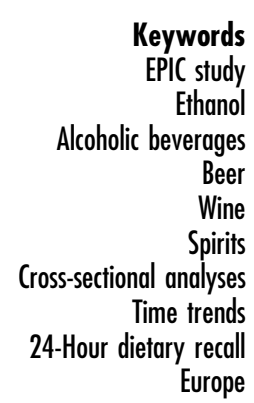

Keywords

EIC study

Ethanol

Beer

Wine

Spirits

Time trends

Europe 
Ethanol intake has been studied intensively as a risk factor for chronic diseases. There is evidence that ethanol intake influences the risk of liver disease, hypertension, osteoporosis $^{1,2}$, cancers of the upper digestive and respiratory tracts, and possibly cancers of the breast and colon-rectum ${ }^{3}$. Heavy drinking has been associated with an increased risk of coronary heart disease and haemorrhagic stroke, whereas light to moderate ethanol consumption has been associated with a reduced risk of coronary heart disease, total and ischaemic stroke and total mortality ${ }^{1,2,4}$.

Studies on trends in ethanol intake $e^{5-8}$ showed that ethanol intake and type of alcoholic beverage consumed are unlikely to be constant over time; therefore, doseresponse relationships between ethanol intake and risk assessment might be distorted when current intake is assessed instead of lifetime use ${ }^{9}$. Assessment of current ethanol intake should therefore be complemented by assessment of ethanol intake at several discrete time points. This provides additional information on lifetime history of ethanol intake that might even be as relevant to the development of chronic disease as current intake.

In the cohorts contributing to the European Prospective Investigation into Cancer and Nutrition (EPIC), data on past alcoholic beverage consumption were obtained retrospectively from each study participant by means of a lifestyle questionnaire standardised across the countries participating in EPIC. The present paper describes trends of self-reported past consumption of alcoholic beverages and ethanol intake, from 1950 to 1995 , within the EPIC cohort.

\section{Subjects and methods}

\section{The EPIC study}

The EPIC project is an ongoing, multi-centre prospective cohort study on diet and cancer that currently includes 519978 middle-aged men and women in 27 study centres in 10 European countries. Participant eligibility within each cohort was defined based on a geographical area or a political boundary, a source population from which potential participants were identified, and in some cases additional criteria including but not limited to age at enrolment in the study. Study populations were a sample of convenience, i.e. subjects came from varying source populations, such as the general population, cancerscreening programmes, nation-wide health insurance programmes or blood donor associations, as previously described in detail ${ }^{10,11}$. In France, Norway, Utrecht (The Netherlands) and Naples (Italy), only women cohorts are involved. One of the most important features of this project is its size, geographical distribution and the heterogeneity of the dietary patterns and other lifestyle characteristics of the study population. More details on the EPIC study design, the study cohort populations, recruitment procedures and participation rates have been reported elsewhere ${ }^{10,11}$.

\section{Study population}

Subjects for the present analysis came from 21 EPIC study centres in eight European countries: Denmark, France, Germany, Greece, Italy, The Netherlands, Spain and the UK. Study centres in Naples (Italy), Bilthoven (The Netherlands), Malmö and Umeå (Sweden), and the South \& East and North \& West regions in Norway were excluded owing to a lack of data on past alcohol consumption. The numbers of subjects in each study centre and country are given in Table 1 . Subjects younger than 35 years $(n=24701$; age range $19-34$ years $)$ and older than 75 years ( $n=1966$; age range $76-107$ years) were excluded from analysis because those age groups were minorities only recruited in certain study centres. Furthermore, subjects with missing alcohol consumption data were excluded from the analysis, resulting in a total of 392064 subjects (275249 women and 116815 men) available for the present investigation.

\section{Retrospective assessment of alcobol consumption}

Self-administered lifestyle questionnaires standardised for core questions across the countries in EPIC were used to

Table 1 Number and origin of study participants* in the European Prospective Investigation into Cancer and Nutrition (EPIC)

\begin{tabular}{|c|c|c|c|}
\hline Country and centre & Abbreviation & Women $(n)$ & $\operatorname{Men}(n)$ \\
\hline \multicolumn{4}{|l|}{ Greece } \\
\hline Greece & GR & 16432 & 11522 \\
\hline \multicolumn{4}{|l|}{ Spain } \\
\hline Granada & $\mathrm{E} 1$ & 6076 & 1795 \\
\hline Murcia & E2 & 5830 & 2684 \\
\hline Navarra & E3 & 4057 & 3785 \\
\hline San Sebastian & E4 & 4259 & 4158 \\
\hline Asturias & E5 & 5448 & 3084 \\
\hline \multicolumn{4}{|l|}{ Italy } \\
\hline Ragusa & 11 & 3263 & 2929 \\
\hline Florence & 12 & 9963 & 3458 \\
\hline Turin & 13 & 4263 & 5655 \\
\hline Varese & 14 & 9491 & 2551 \\
\hline \multicolumn{4}{|l|}{ France } \\
\hline South coast & $\mathrm{F} 1$ & 9615 & - \\
\hline South & $\mathrm{F} 2$ & 17978 & - \\
\hline North-west & F3 & 11405 & - \\
\hline North-east & $\mathrm{F} 4$ & 32235 & - \\
\hline \multicolumn{4}{|l|}{ Germany } \\
\hline Heidelberg & D1 & 13616 & 11927 \\
\hline Potsdam & D2 & 16636 & 10895 \\
\hline \multicolumn{4}{|l|}{ The Netherlands } \\
\hline Utrecht & $\mathrm{NL}$ & 17234 & - \\
\hline \multicolumn{4}{|l|}{ United Kingdom } \\
\hline General population & GB1 & 14447 & 12370 \\
\hline 'Health-conscious' & GB2 & 43440 & 13010 \\
\hline \multicolumn{4}{|l|}{ Denmark } \\
\hline Copenhagen & DK1 & 20865 & 18579 \\
\hline Aarhus & DK2 & 8696 & 8413 \\
\hline Total & & 275249 & 116815 \\
\hline
\end{tabular}

* Number of subjects consuming beer/cider, wine or sweet liqueur/distilled spirits at the age of 20 years. 
estimate the number of standard glasses per day or week expressed as beer and/or cider, wine, and sweet liqueur and/or distilled spirits. Depending on the study centre, information on the amount of alcoholic beverages consumed at 20,30, 40 or 50 years of age was obtained retrospectively. Because consumption of alcoholic beverages at age 50 was only asked in the Italian and Danish study centres, analysis was restricted to data obtained at age 20, 30 and 40 years. No information on self-reported past alcohol consumption at age 30 was available for the cohort in Utrecht (The Netherlands) or at age 40 for the British cohorts. Ethanol intake $\left(\mathrm{g} \mathrm{day}^{-1}\right)$ for the time periods 1950-1975, 1960-1985 and 1970-1995 was calculated based on average glass volume and ethanol content for each type of alcoholic beverage (i.e. beer/cider, wine and sweet liqueur/distilled spirits). This information was derived for each study centre from 36900 computerised 24-hour dietary recall interviews collected from March 1995 to June 2000 in the EPIC calibration substudy, using a standardised computerised methodological classification system (EPIC-SOFT) $^{12,13}$, common across countries. This makes allowance for the different ethanol contents of beverages consumed by the different centres. Average ethanol content (g)/glass for alcoholic beverages estimated from the 24-hour dietary recalls for the EPIC study centres is shown in Table 2 .

\section{Data analysis}

The date of birth of participants was used to calculate calendar time when participants were 20, 30 or 40 years

Table 2 Average ethanol content $(\mathrm{g}) / \mathrm{glass}$ for alcoholic beverages, estimated from the 24-hour dietary recalls, for the European Prospective Investigation into Cancer and Nutrition (EPIC) study centres

\begin{tabular}{|c|c|c|c|c|}
\hline Country and centre & Sex & $\begin{array}{l}\text { Grams of ethanol } \\
\text { per glass of beer/cider }\end{array}$ & $\begin{array}{l}\text { Grams of ethanol } \\
\text { per glass of wine }\end{array}$ & $\begin{array}{c}\text { Grams of ethanol } \\
\text { per glass of sweet liqueur/distilled } \\
\text { spirits }\end{array}$ \\
\hline \multicolumn{5}{|l|}{ Greece } \\
\hline \multirow{2}{*}{ Greece } & Male & 7.2 & 12.5 & 24.5 \\
\hline & Female & 5.7 & 9.1 & 16.0 \\
\hline \multicolumn{5}{|l|}{ Spain } \\
\hline \multirow[t]{2}{*}{ Granada } & Male & 6.7 & 13.8 & 17.9 \\
\hline & Female & 5.8 & 9.9 & 14.7 \\
\hline \multirow[t]{2}{*}{ Murcia } & Male & 6.6 & 14.4 & 15.3 \\
\hline & Female & 5.8 & 9.1 & 16.1 \\
\hline \multirow[t]{2}{*}{ Navarra } & Male & 3.7 & 13.1 & 20.4 \\
\hline & Female & 4.0 & 7.9 & 13.3 \\
\hline \multirow[t]{2}{*}{ San Sebastian } & Male & 7.6 & 15.1 & 19.5 \\
\hline & Female & 4.0 & 8.6 & 11.6 \\
\hline \multirow[t]{2}{*}{ Asturias } & Male & 6.6 & 17.0 & 17.3 \\
\hline & Female & 6.1 & 10.5 & 10.5 \\
\hline \multicolumn{5}{|l|}{ Italy } \\
\hline \multirow[t]{2}{*}{ Ragusa } & Male & 5.2 & 12.1 & 7.3 \\
\hline & Female & 2.9 & 7.1 & 3.9 \\
\hline \multirow[t]{2}{*}{ Florence } & Male & 5.6 & 10.6 & 10.4 \\
\hline & Female & 4.2 & 8.0 & 7.8 \\
\hline \multirow[t]{2}{*}{ Turin } & Male & 5.7 & 13.5 & 9.2 \\
\hline & Female & 4.1 & 9.4 & 7.5 \\
\hline \multirow[t]{2}{*}{ Varese } & Male & 6.1 & 13.6 & 9.9 \\
\hline & Female & 5.0 & 7.5 & 8.0 \\
\hline \multicolumn{5}{|l|}{ France } \\
\hline South coast & Female & 5.4 & 9.4 & 15.1 \\
\hline South & Female & 7.1 & 9.2 & 14.5 \\
\hline North-west & Female & 6.9 & 9.2 & 17.2 \\
\hline North-east & Female & 6.7 & 10.1 & 16.9 \\
\hline \multicolumn{5}{|l|}{ Germany } \\
\hline \multirow[t]{2}{*}{ Heidelberg } & Male & 12.5 & 16.1 & 22.9 \\
\hline & Female & 9.5 & 14.7 & 19.3 \\
\hline \multirow{2}{*}{ Potsdam } & Male & 13.7 & 14.1 & 20.6 \\
\hline & Female & 9.6 & 14.1 & 16.2 \\
\hline \multicolumn{5}{|l|}{ The Netherlands } \\
\hline \multirow{2}{*}{\multicolumn{5}{|c|}{$\begin{array}{l}\text { Utrecht } \\
\text { United Kingdom }\end{array}$}} \\
\hline & & & & \\
\hline \multirow[t]{2}{*}{ General population } & Male & 9.4 & 16.4 & 21.5 \\
\hline & Female & 9.0 & 15.0 & 17.8 \\
\hline \multirow[t]{2}{*}{ 'Health conscious' } & Male & 9.4 & 13.4 & 21.5 \\
\hline & Female & 9.0 & 12.4 & 17.8 \\
\hline \multicolumn{5}{|l|}{ Denmark } \\
\hline \multirow[t]{2}{*}{ Copenhagen } & Male & 10.7 & 16.0 & 11.7 \\
\hline & Female & 9.0 & 15.0 & 10.5 \\
\hline \multirow[t]{2}{*}{ Aarhus } & Male & 9.4 & 17.3 & 14.1 \\
\hline & Female & 7.1 & 16.1 & 9.9 \\
\hline
\end{tabular}


old and to construct corresponding time periods: information on consumption of alcoholic beverages at age 20 corresponds to information on alcoholic beverage consumption during the time period 1950-1975, information at age 30 to the time period 1960-1985, and information at age 40 to the time period 1970-1995. Because of the wide age range (35-75 years) of study participants and the availability of information on consumption of alcoholic beverages at given ages (20, 30 and 40 years), we were able to calculate the average consumption of alcoholic beverages (glass week ${ }^{-1}$ ) and ethanol intake $\left(\mathrm{g} \mathrm{day}^{-1}\right)$ for the time periods 1950-1975 (at age 20), 1960-1985 (at age 30) and 1970-1995 (at age 40) in the study centres.

The percentage of alcohol abstainers was determined. Contribution of alcoholic beverages to ethanol intake was calculated as outlined above. Linear regression analysis was conducted to assess trends in past alcoholic beverage consumption and ethanol intake with time for 1950-1975, 1960-1985 and 1970-1995 for the study centres. In the regression model, number of glasses of alcohol (i.e. beverages) per week and respectively grams of ethanol per day was the dependent variable and calendar year of consumption was the independent variable. All analyses were performed separately for men and women.

Statistical analysis was performed by use of the SAS ${ }^{\circledR}$ statistical software package, version 6.12 (SAS Institute, Inc., Cary, NC, USA).

\section{Results}

Trends for self-reported consumption of alcoholic beverages with time are depicted in Fig. 1, 3 and 5 separately for men and women. Figure 7 delineates information on time trends of ethanol intake. The figures describe the yearly increase or decrease in alcoholic beverage consumption and ethanol intake for the study centres (see Table 1 for abbreviations) over the time periods of interest, i.e. 1950-1975, 1960-1985 and 19701995. The annual increase/decrease of alcoholic beverage
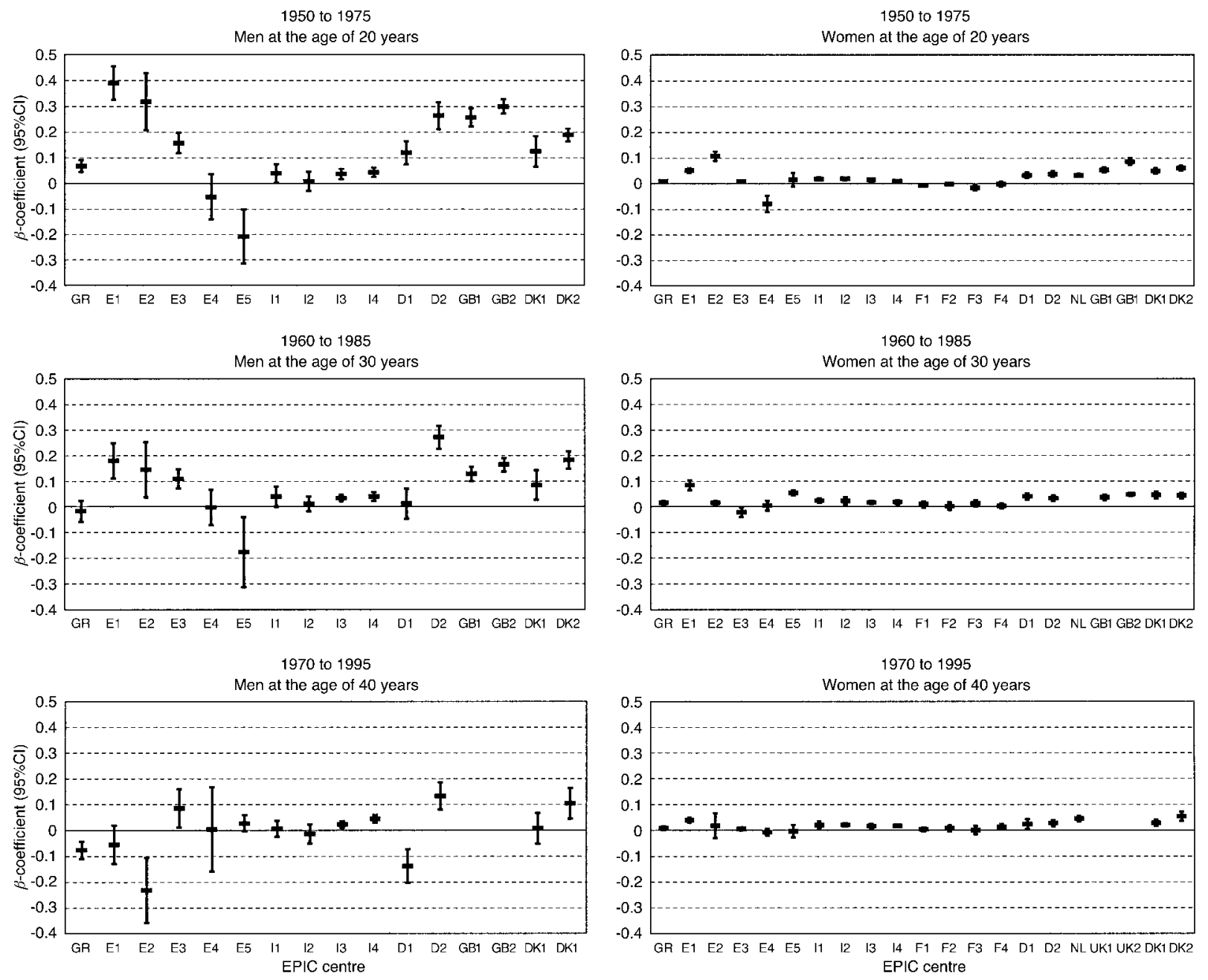

Fig. 1 Trends in self-reported past beer/cider consumption (glass week ${ }^{-1}$ ) for the time periods 1950-1975, 1960-1985 and $1970-1995$ for the European Prospective Investigation into Cancer and Nutrition (EPIC) study centres. Yearly increase/decrease of past beer/cider intake expressed as $\beta$-coefficient (95\% confidence interval, $\mathrm{Cl}$ ). See Table 1 for abbreviations of EPIC cohorts 
1950

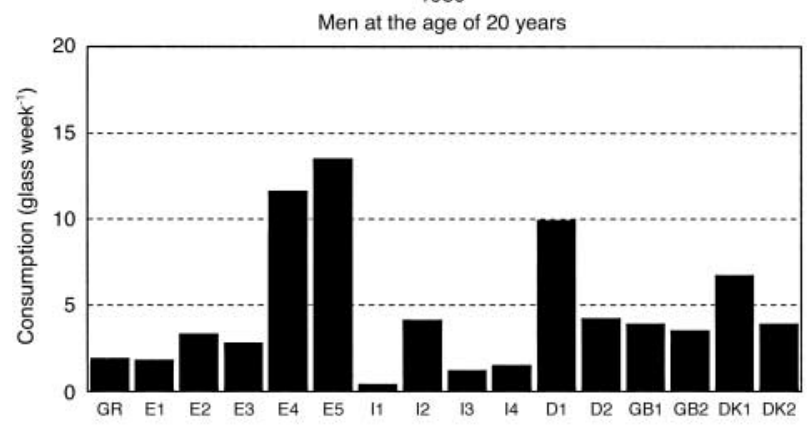

1960

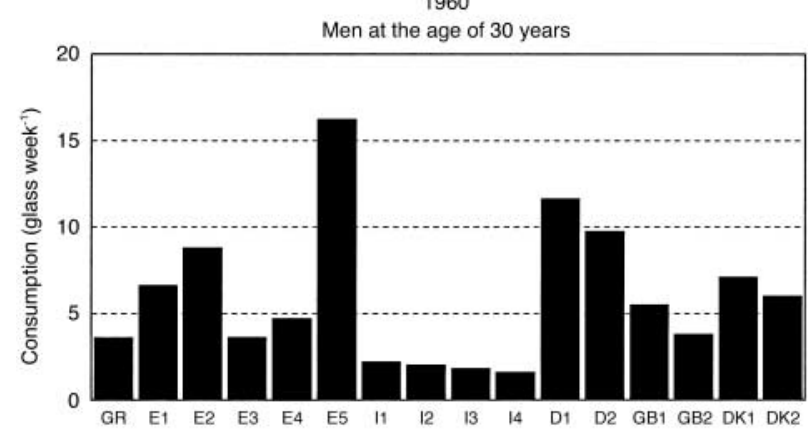

1970

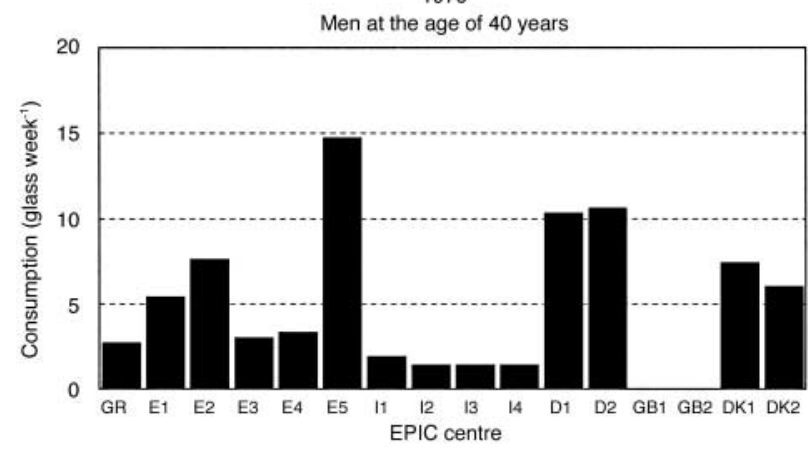

1950

Women at the age of 20 years

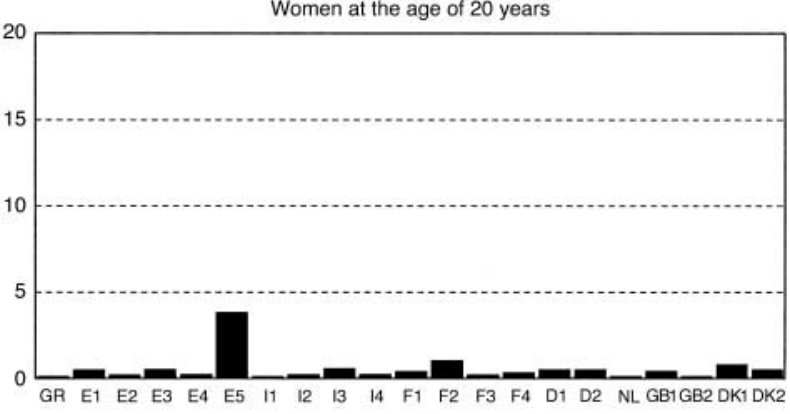

1960

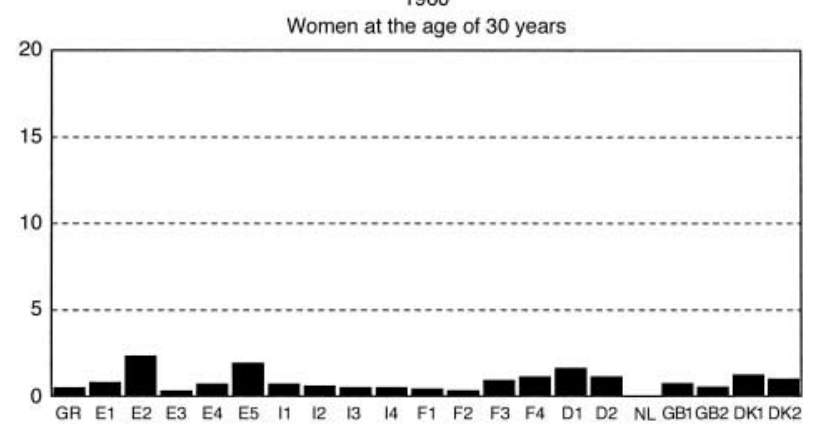

1970

Women at the age of 40 years

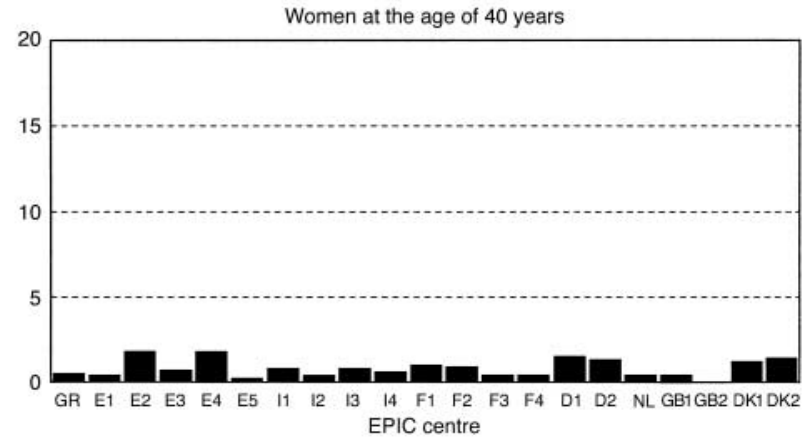

Fig. 2 Level of self-reported past beer/cider consumption (glass week ${ }^{-1}$ ) in 1950, 1960 and 1970 for the European Prospective Investigation into Cancer and Nutrition (EPIC) study centres. See Table 1 for abbreviations of EPIC cohorts

consumption (glass week ${ }^{-1}$ ) and ethanol intake $\left(\mathrm{g} \mathrm{day}^{-1}\right.$ ) is expressed as $\beta$-coefficient of the linear regression, reflecting the annual change of alcoholic beverage consumption (glassweek ${ }^{-1}$ ) and ethanol intake $\left(\mathrm{g} \mathrm{day}^{-1}\right)$. This means, for example, that a $\beta$-coefficient of 0.26 for male beer/cider consumption observed for the time period 1950-1975 in the study centre in Potsdam, Germany (Fig. 1) indicates an annual increase of beer/cider consumption of 0.26 glasses per week. This is equivalent to an increase of beer/cider consumption of 6.5 glasses a week over a time period of 25 years. The corresponding 95\% confidence intervals indicate the precision of the estimate of a yearly increase or decrease in consumption or intake. In our example, the annual increase of beer/cider consumption is within the range of 0.21 to 0.32 glasses week ${ }^{-1}$ for men in the study centre in Potsdam. We observed that the regression coefficient is related to the initial level of alcoholic beverage consumption and ethanol intake. Therefore, the levels of alcoholic beverage consumption (glass week ${ }^{-1}$ ) and ethanol intake $\left(\mathrm{g} \mathrm{day}^{-1}\right)$ in 1950, 1960 and 1970 are presented graphically in Figs. 2, 4 and 6 to facilitate the interpretation.

Self-reported beer/cider consumption generally increased across all time periods, i.e. 1950-1975, 19601985 and 1970-1995, for most of the study centres (Fig. 1). For men there was a marked increase in beer/cider consumption $\left(>0.1\right.$ glass week ${ }^{-1}$ per year) in the study centres in Granada, Murcia and Navarra in Spain (19501975, 1960-1985), in the German centres of Heidelberg (1950-1975) and Potsdam (1950-1975, 1960-1985, 1970-1995), in the British study centres (1950-1975, 1960-1985) and in the Danish centres of Copenhagen (1950-1975) and Aarhus (1950-1975, 1960-1985). The increase in beer/cider consumption was most pronounced in those study centres with lower average beer/cider consumption during the years 1950, 1960 or 1970, with the exception of the study centres in Greece and Italy (Fig. 2). For the study centres in Granada and Murcia, where from 

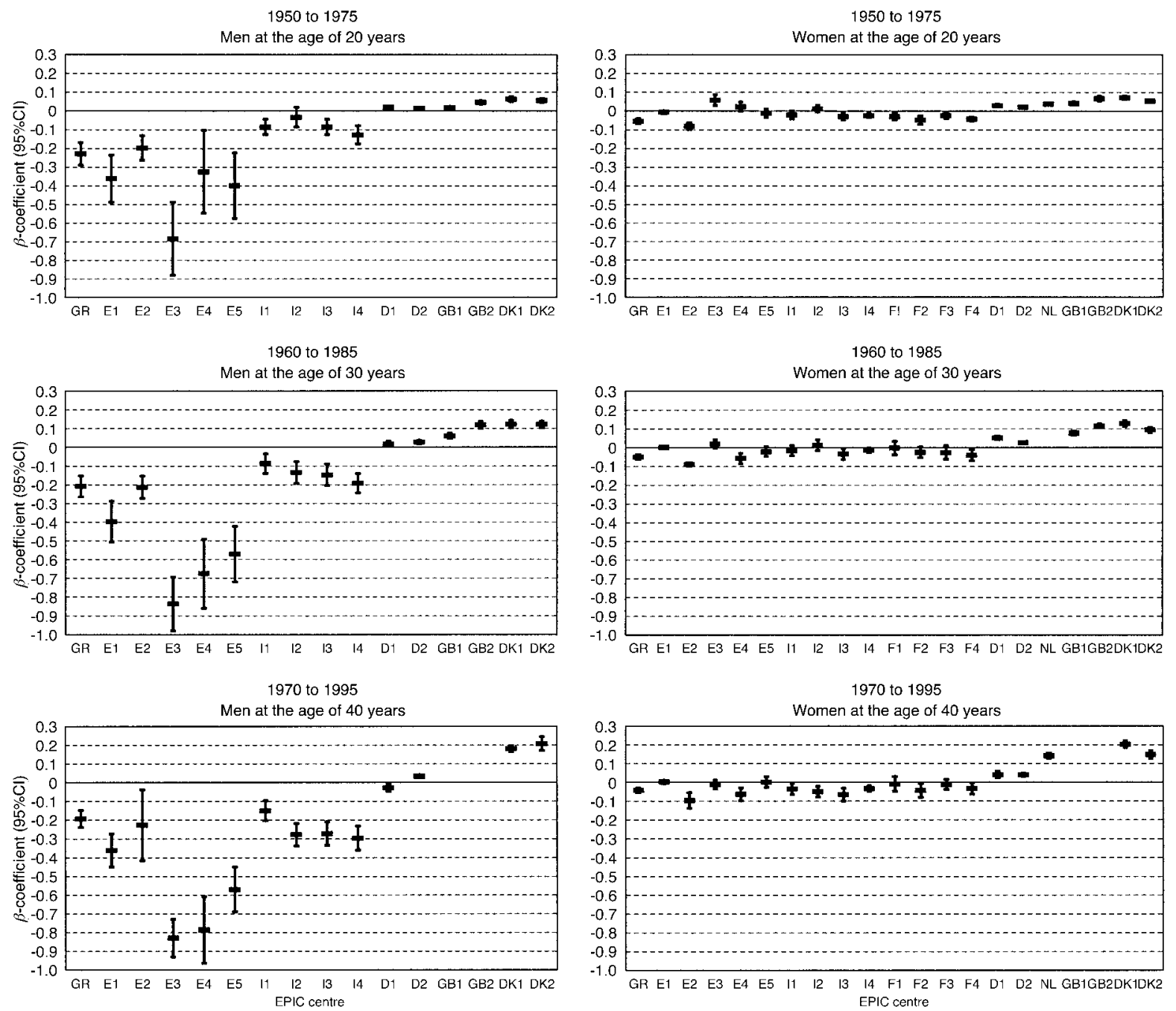

Fig. 3 Trends in self-reported past wine consumption (glass week $^{-1}$ ) for the time periods $1950-1975,1960-1985$ and $1970-1995$ for the European Prospective Investigation into Cancer and Nutrition (EPIC) study centres. Yearly increase/decrease of past wine intake expressed as $\beta$-coefficient (95\% confidence interval, $\mathrm{Cl}$ ). See Table 1 for abbreviations of EPIC cohorts

1950 to 1975 and from 1960 to 1985 an annual increase in beer/cider consumption was observed, consumption decreased from 1970 to 1995. A similar trend could be observed for the study centre in Heidelberg. In contrast, in the Spanish study centres of San Sebastian and Asturias, beer/cider consumption decreased from 1950 to 1975 and from 1960 to 1985 and increased from 1970 to 1995 .

Trends in beer/cider consumption were considerably less pronounced for women than for men, ranging from -0.8 glass week $^{-1}$ per year (San Sebastian, Spain) to 0.11 glass week $^{-1}$ per year (Murcia, Spain) in 1950-1975, from -0.02 glass week $^{-1}$ per year (Navarra, Spain) to 0.08 glass week $^{-1}$ per year (Granada, Spain) in 19601985 , and from -0.01 glass week $^{-1}$ per year (Navarra) to 0.05 glass week $^{-1}$ per year (Aarhus, Denmark) in 19701995. For men in the middle/northern European study centres, self-reported beer/cider consumption was the major contributor to ethanol intake for the time periods 1950-1975 and 1960-1985. For the time period 1970-
1995, however, the major contributor to ethanol intake in the Danish cohort in Aarhus shifted from self-reported beer/cider to wine consumption.

Trends in wine consumption differed according to geographical location: for men in southern European study centres, a downward trend in wine consumption was observed for all time periods, whereas for men of middle/north European study centres, an upward trend was observed (Fig. 3). This observation was most pronounced for the Spanish centres of Navarra, San Sebastian and Asturias, with consistent marked decreases in wine consumption for all time periods (range, -0.32 to -0.84 glass week $^{-1}$ per year), and the Danish study centres with consistent increases of wine consumption for all time periods (range, $0.06-0.020$ glass week $^{-1}$ per year). The level of initial wine consumption was considerably higher in southern than in middle/northern European study centres (Fig. 4). Similar, although less pronounced trends were observed for women. Self-reported wine 


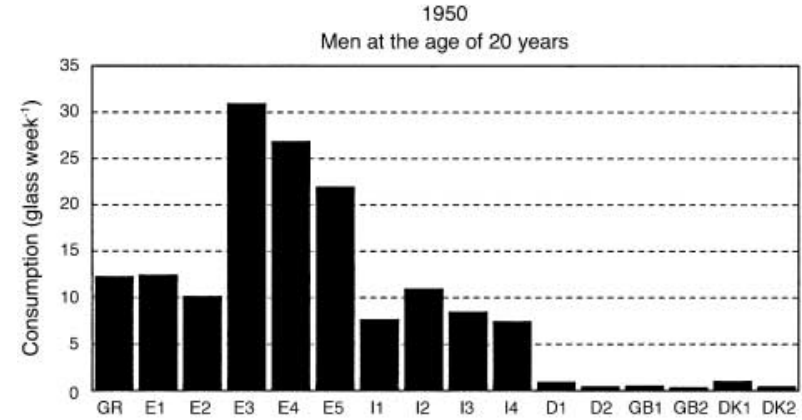

1950

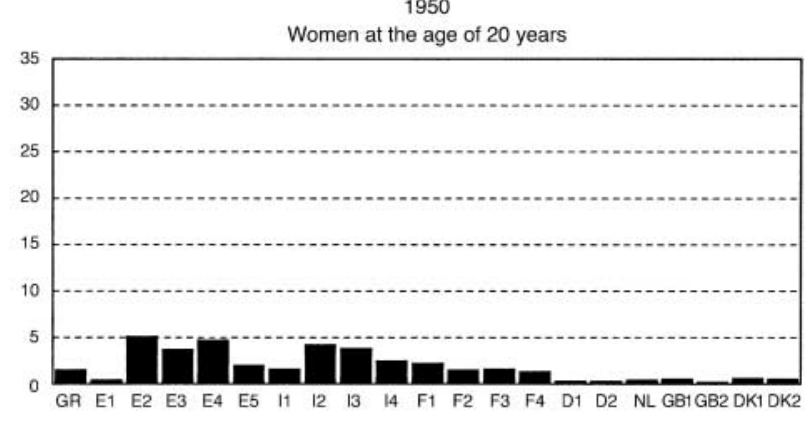

1960

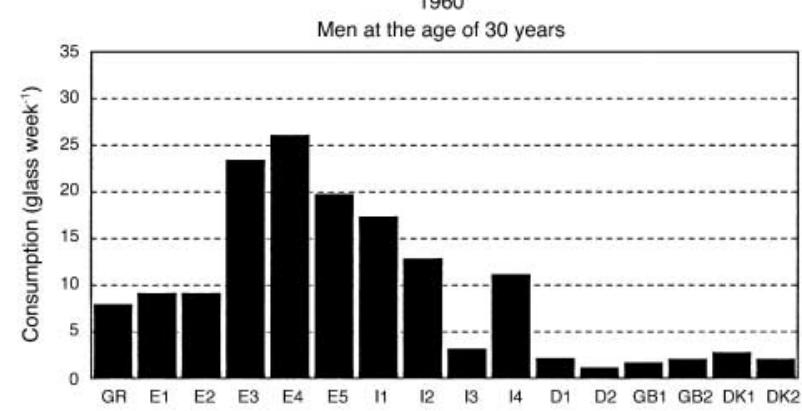

1960

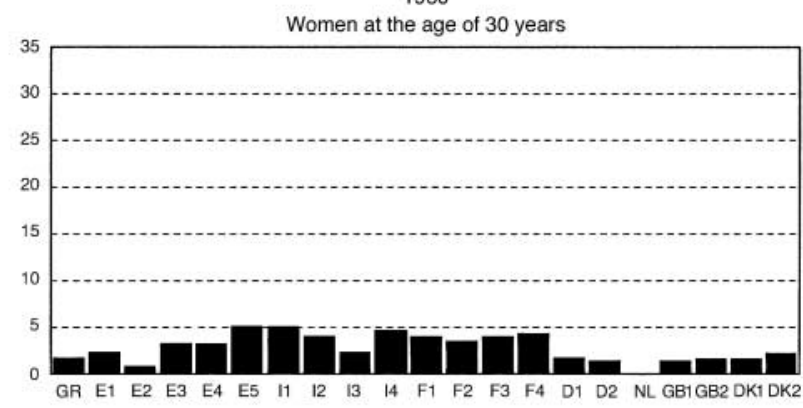

1970

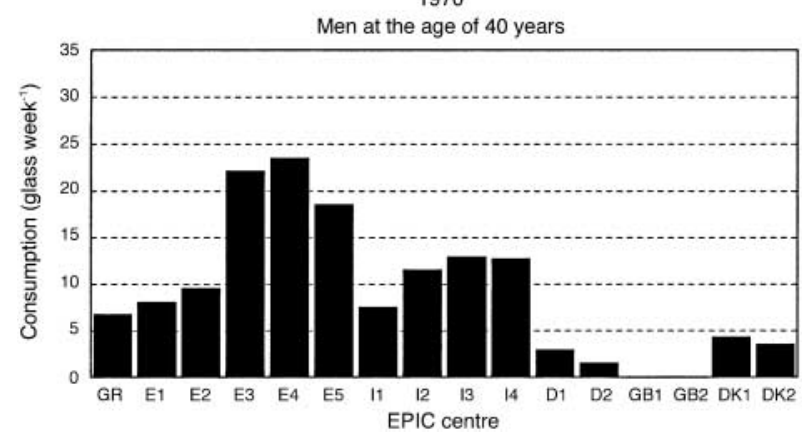

1970

Women at the age of 40 years

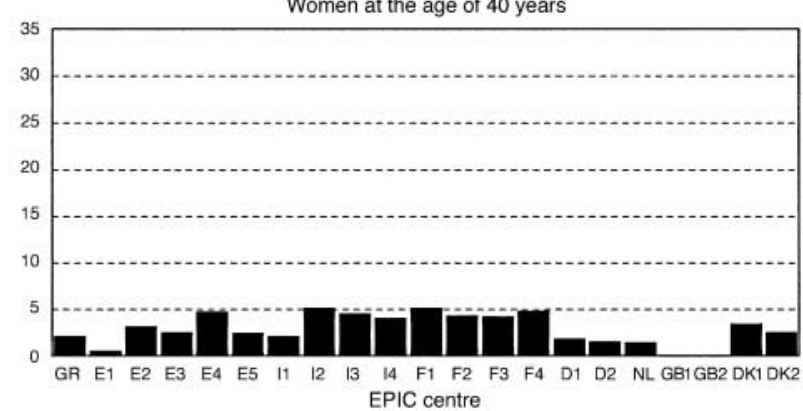

Fig. 4 Level of self-reported past wine consumption (glass week ${ }^{-1}$ ) in 1950, 1960 and 1970 for the European Prospective Investigation into Cancer and Nutrition (EPIC) study centres. See Table 1 for abbreviations of EPIC cohorts

consumption was the major contributor to ethanol intake for all time periods for both men and women in the southern European study centres and also for women in the middle/northern European study centres (except for the British and Dutch cohorts during the time period 1950-1975).

For consumption of sweet liqueur/distilled spirits (Fig. 5), the following was observed for men: generally an increase for the time period 1950-1975 (except for the study centres in Greece and in Florence, Italy); slight increases for most study centres for the time period 19601985; and in general a decrease for the time period 19701995. For the study centre in Greece, a consistent decrease of sweet liqueur/distilled spirits consumption was observed (ranging from -0.09 glass week $^{-1}$ per year in $1950-1975$ to -0.13 glass week ${ }^{-1}$ per year in $1970-1995$ ). For women, only minor changes were observed, with the exception of the British study centres for which a marked yearly increase of sweet liqueur/distilled spirits consumption could be observed ( 0.6 glass week ${ }^{-1}$ per year for
1950-1975, 0.3 glass week $^{-1}$ per year for 1960-1985). For the time period 1950-1975, self-reported sweet liqueur/ distilled spirits consumption was the major contributor to ethanol intake in British women.

Time trends for self-reported past ethanol intake are depicted in Fig. 7. Because self-reported past wine consumption was the predominant contributor to ethanol intake, the plots in Fig. 7 show a similar geographical pattern to those delineating time trends for wine consumption (Fig. 3). For men, changes were most marked for the study centre in Greece and the Spanish centres of Navarra, San Sebastian and Asturias, where considerable consistent decreases in alcohol intake were seen for all time periods $\left(-0.57\right.$ to $-0.74 \mathrm{~g}$ ethanol day ${ }^{-1}$ per year for the study centre in Greece; -0.63 to $-1.36 \mathrm{~g}$ ethanol $\mathrm{day}^{-1}$ per year for the three study centres in Spain). In contrast, consistent moderate increases in ethanol intake over all time periods were observed for the study centres in Potsdam, Germany (range, 0.11$0.43 \mathrm{~g}$ ethanol day ${ }^{-1}$ per year), the UK (range, $0.32-0.50 \mathrm{~g}$ 

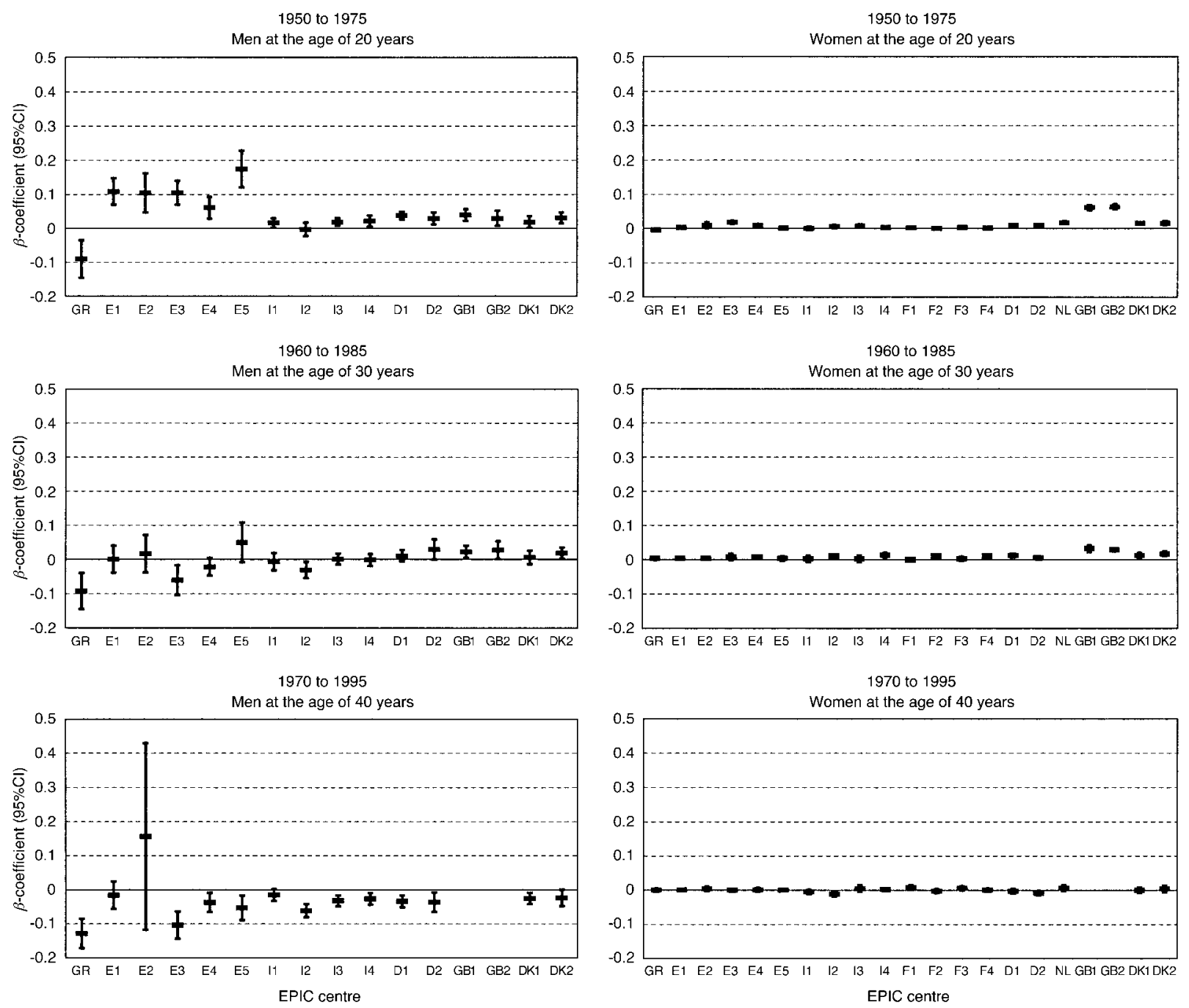

Fig. 5 Trends in self-reported past sweet liqueur/distilled spirits consumption (glass week ${ }^{-1}$ ) for the time periods 1950-1975, 19601985 and 1970-1995 for the European Prospective Investigation into Cancer and Nutrition (EPIC) study centres. Yearly increase/ decrease of past sweet liqueur/distilled spirits intake expressed as $\beta$-coefficient (95\% confidence interval, $\mathrm{Cl}$ ). See Table 1 for abbreviations of EPIC cohorts

ethanol day ${ }^{-1}$ per year) and Denmark (range, 0.28-0.51 g ethanol day ${ }^{-1}$ per year). For women, changes were rather modest; ethanol intake seemed to increase consistently over all time periods for the British (range, 0.29-0.38g ethanol day ${ }^{-1}$ per year) and Danish (range, $0.21-0.47 \mathrm{~g}$ ethanol day ${ }^{-1}$ per year) cohorts. Changes seemed to be associated with the initial level of ethanol intake (Fig. 8) That is, the study centres with higher levels of ethanol intake in 1950, 1960 and 1970 show higher negative regression coefficients for the corresponding time periods (1950-1975, 1960-1985 and 1970-1995) than centres with lower ethanol intakes.

The percentage of abstainers, i.e. study participants not reporting any consumption of beer/cider, wine and sweet liqueur/distilled spirits, is shown in Fig. 9. In general, a higher percentage of women reported no consumption of alcoholic beverages compared with men. The average percentage of male alcohol abstainers was $11.7 \%$ (range,
$5.4 \%$ (UK general population) to 39.6\% (Greece)) for 1950-1975, 6.8\% (range, 1.5\% (Potsdam, Germany) to $21.6 \%$ (UK 'health-conscious' population)) for 1960-1985, and $5.3 \%$ (range, $3.7 \%$ (Potsdam) to $21.1 \%$ (Granada, Spain)) for 1970-1995. The figures for female alcohol abstainers were $46.5 \%$ (range, $16.8 \%$ (Potsdam) to $77.2 \%$ (Granada)), $29.4 \%$ (range, $4.8 \%$ (Potsdam) to $73.5 \%$ (Granada)), and $22.9 \%$ (range, $3.7 \%$ (Potsdam) to $71.3 \%$ (Granada)). For most cohorts, a considerable decrease in the percentage of alcohol abstainers was observed, with the exception of the Spanish centres of Navarra (both sexes) and San Sebastian (males), where an increase in numbers of alcohol abstainers was noted.

Generally, men reported higher ethanol intakes than women. The average male/female ratio for self-reported past ethanol intake was 5.8 (range, 2.4 (UK general population) to 16.2 (Granada, Spain)) for 1950-1975, 5.2 (range, 2.1 (UK general population) to 15.5 (Granada)) for 

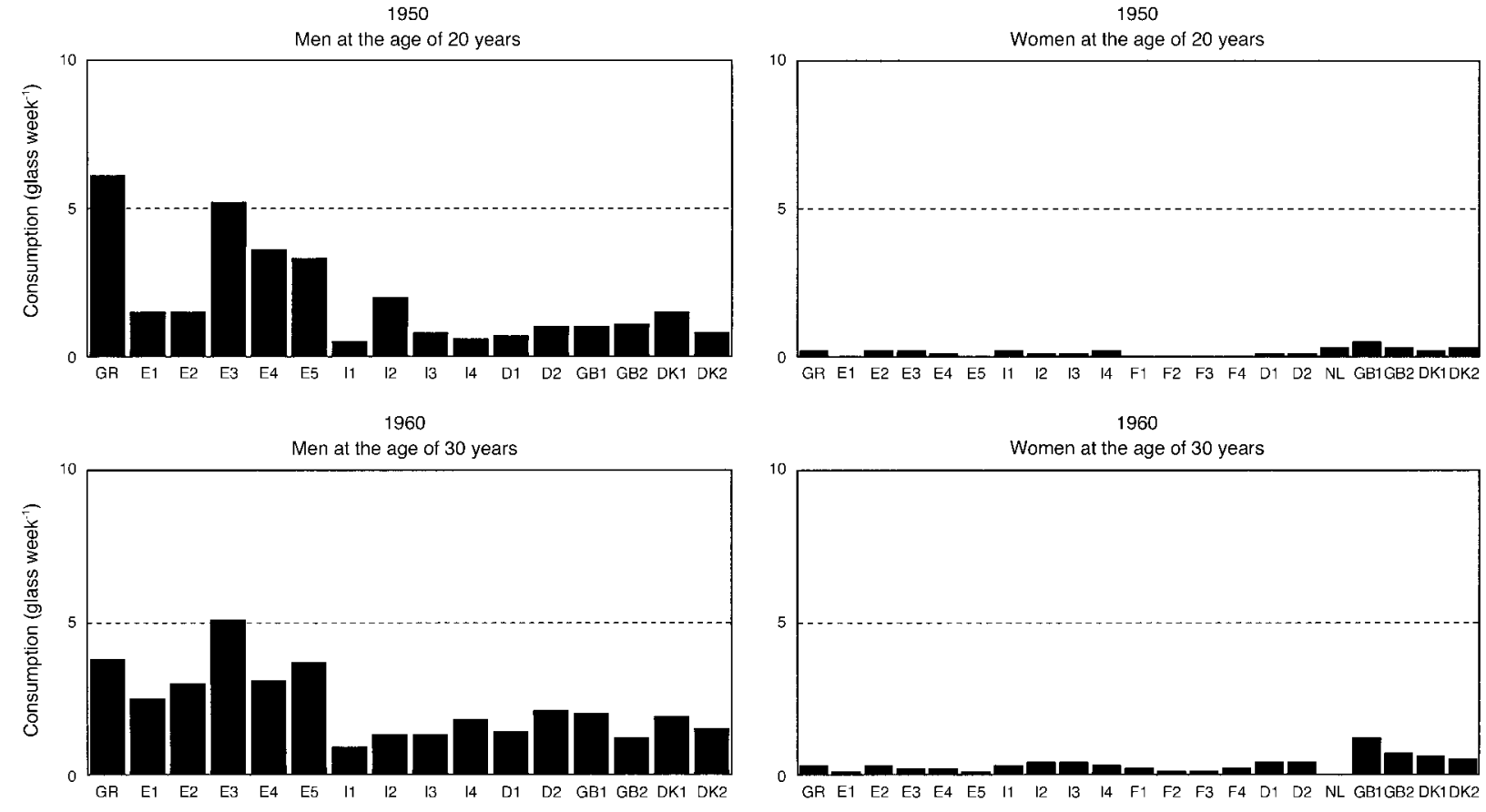

1970
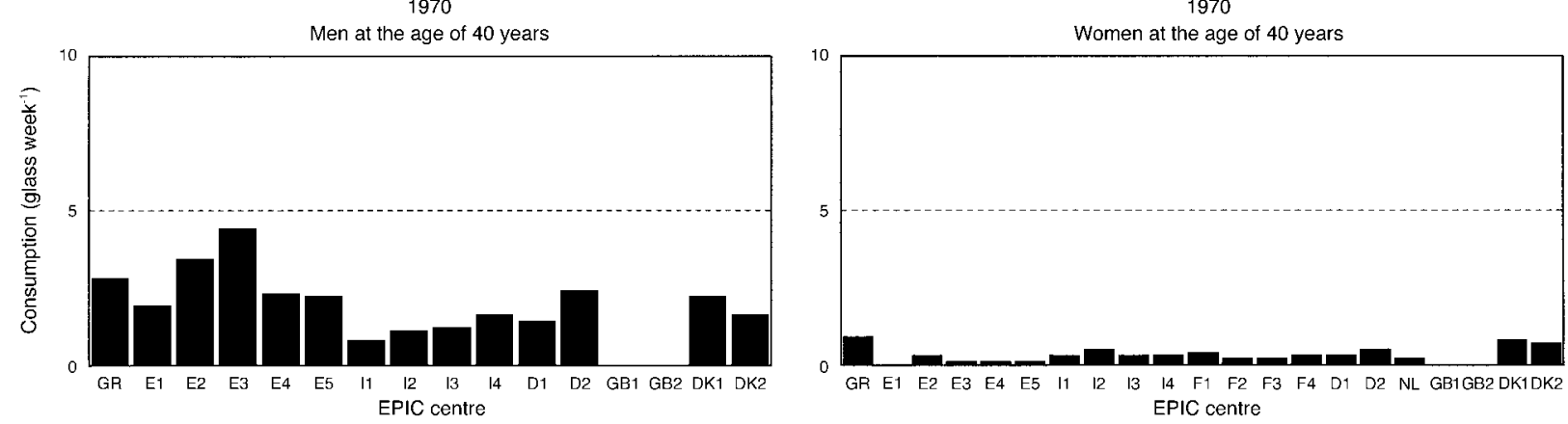

Fig. 6 Level of self-reported past sweet liqueur/distilled spirits consumption (glass week ${ }^{-1}$ ) in 1950, 1960 and 1970 for the European Prospective Investigation into Cancer and Nutrition (EPIC) study centres. See Table 1 for abbreviations of EPIC cohorts

1960-1985, and 5.2 (range, 2.1 (Copenhagen, Denmark) to 14.1 (Granada)) for 1970-1995. The male/female ratio of self-reported ethanol intake was quite high in some of the Spanish study centres (Asturias, Granada, Navarra) and Greece because of the higher proportion of nonconsumers of alcoholic beverages among women compared with men (Fig. 9). For most study centres, however, it was below 5 with moderate changes, mostly slight decreases with time.

\section{Discussion}

The current report describes trends of self-reported past consumption of beer/cider, wine and sweet liqueur/distilled spirits and ethanol intake from 1950-1975, 19601985 and 1970-1995 for 21 study centres in Europe contributing to the EPIC study. Generally, we observed upward trends in beer/cider consumption for most EPIC centres for 1950-1975, 1960-1985 and 1970-1995. Trends in wine consumption differed according to geographical location: downward trends with time were observed for men in southern European EPIC centres, upward trends for those in middle/northern European study centres. For women, similar trends were less pronounced. In general, wine consumption was the major contributor to ethanol intake for both men and women in most study centres. Therefore, time trends for ethanol intake showed a similar geographical pattern to that for wine consumption. More women refrained from alcoholic beverage consumption than men, and generally over time the percentage of alcohol abstainers decreased considerably for most EPIC centres.

Interpretation of our findings should be preceded by methodological considerations. For the current analysis, we were able to assess trends of alcoholic beverage consumption and ethanol intake for three time periods, 1950-1975, 1960-1985 and 1970-1995, using data on selfreported past consumption collected within EPIC. Due to the cross-sectional design of the current analysis, where effects of cohort (i.e. birth year) and period (defined as 

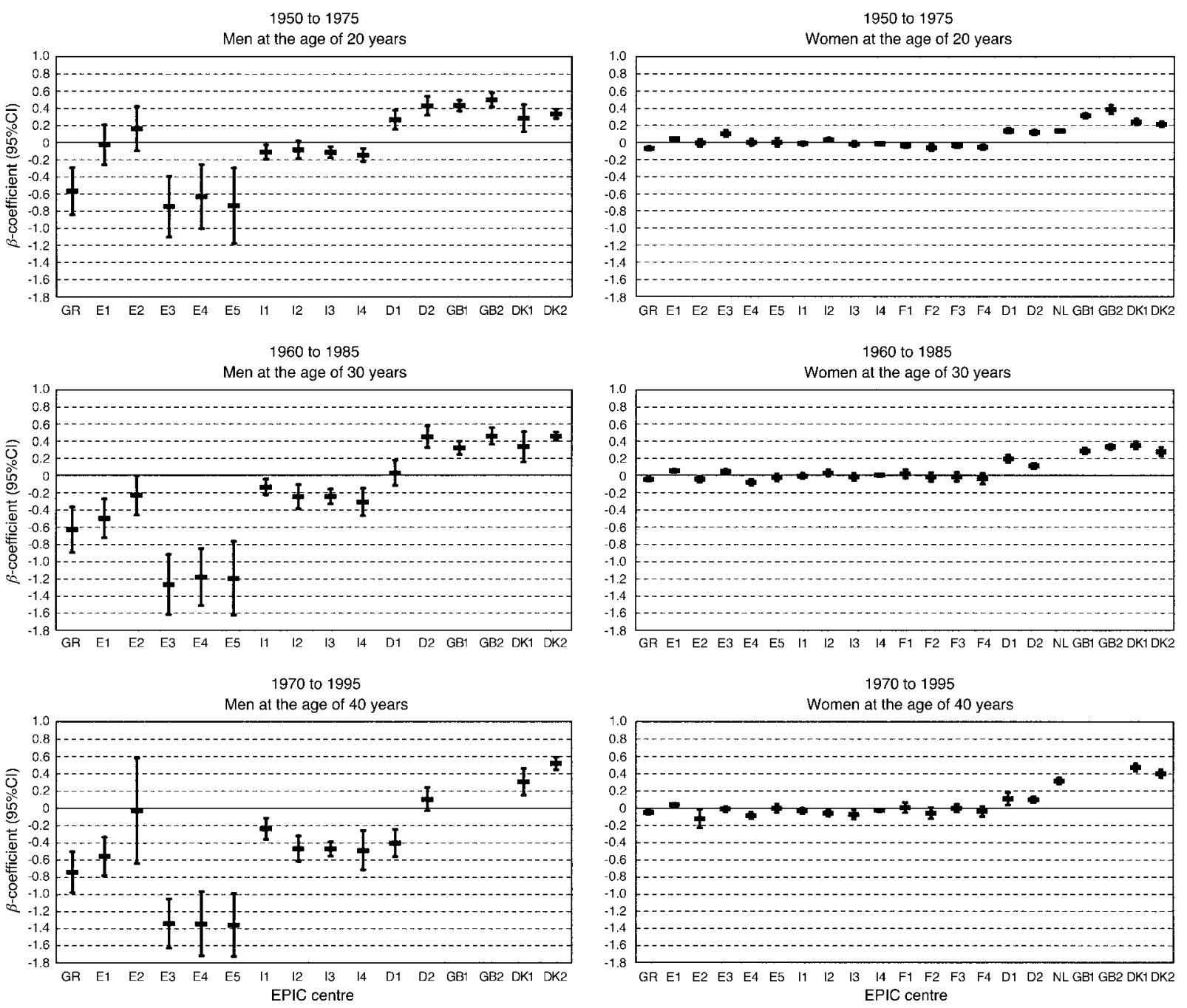

Fig. 7 Trends in self-reported ethanol intake $\left(\mathrm{g} \mathrm{day}^{-1}\right)$ for the time periods $1950-1975,1960-1985$ and $1970-1995$ for the European Prospective Investigation into Cancer and Nutrition (EPIC) study centres. Yearly increase/decrease of past ethanol intake expressed as $\beta$-coefficient $(95 \%$ confidence interval, $\mathrm{Cl})$. See Table 1 for abbreviations of EPIC cohorts

historical influences at the time of measurement) are confounded $^{8}$, disentangling age, period and cohort effects has not been possible. Therefore, and also to facilitate interpretation of our results, our analysis focused on description of time trends and gender differences in alcoholic beverage consumption and ethanol intake within the EPIC cohort.

Self-reported ethanol intake in surveys usually seems to cover only half the amount sold ${ }^{14}$. This may be explained partly by sampling errors, i.e. heavy drinkers may be less likely to participate in surveys, and by response errors, e.g. difficulties in recall of drinking practices and culturally determined socially desirable answers. Underreporting of ethanol intake by individuals is common for all available methods, which does not, however, necessarily mean these methods are not of value. When each individual underreports by a similar proportion, the level of ethanol intake is underestimated, but ranking is maintained. However, when underreporting is non-proportional and different between subjects, ranking is also affected. Therefore, the relationship between ethanol intake and health may then be weakened ${ }^{15}$. Methods of data collection bear directly on the quality of the data being collected on ethanol intake. Within EPIC, assessment of ethanol intake in the past was done retrospectively by use of lifestyle questionnaires specifically asking about the frequency and type of alcoholic beverages consumed at a given age. In line with the idea that the more is asked, the higher the estimate of ethanol intake will be, $\mathrm{Rehm}^{16}$ observed that beverage-specific questions yield higher estimates than questions asking only for ethanol intake. When the type of beverage, such as beer, wine or spirits, was solicited, estimates were about $20 \%$ higher $^{15}$. Estimates for ethanol intake in the EPIC study on the country level were on average around $72 \%$ compared with the per capita consumption data from 1961 to $1995^{17}$. Generally, it seems that there are only small differences in reproducibility between the various techniques and that 
1950

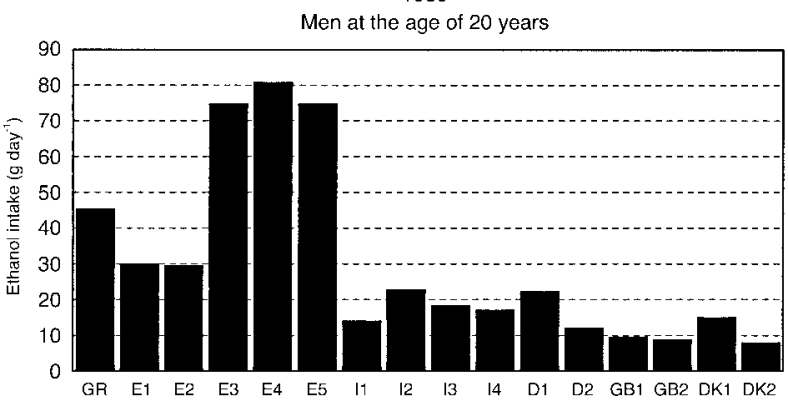

1960

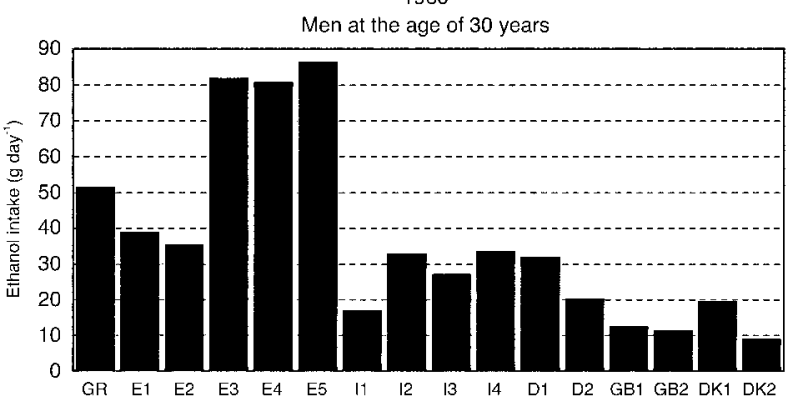

1970

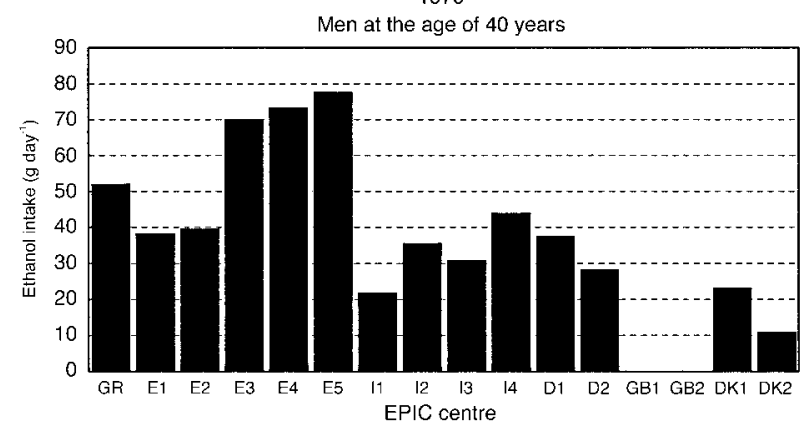

1950

Women at the age of 20 years

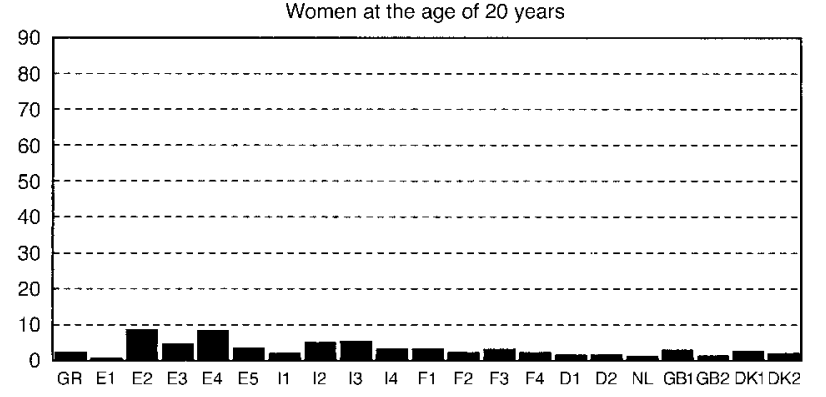

1960

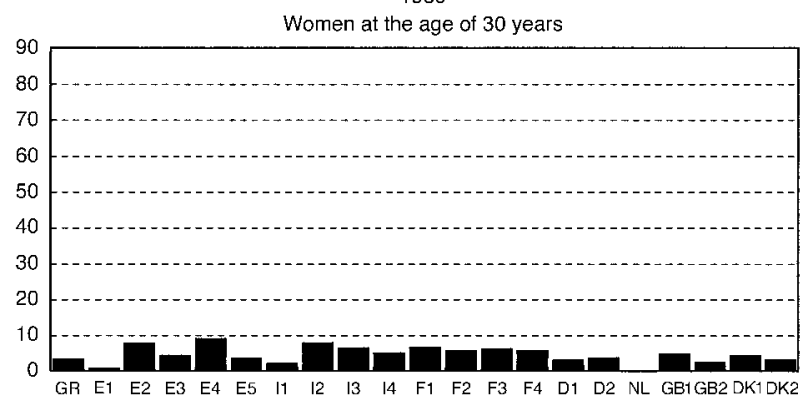

1970

Women at the age of 40 years

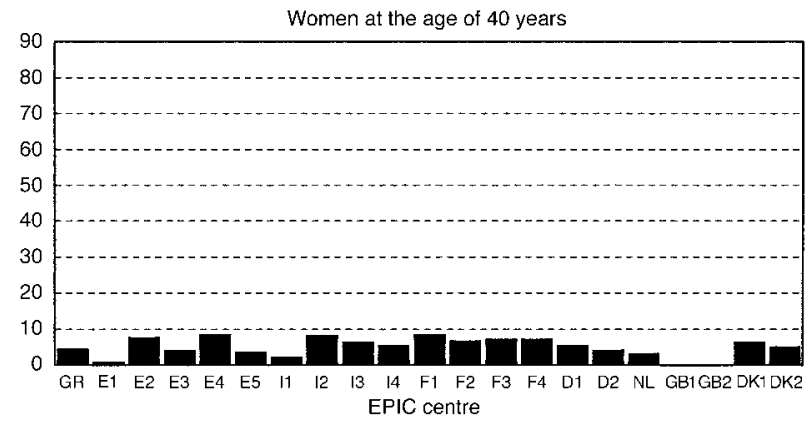

Fig. 8 Level of self-reported ethanol intake $\left(\mathrm{g} \mathrm{day}^{-1}\right)$ in 1950, 1960 and 1970 for the European Prospective Investigation into Cancer and Nutrition (EPIC) study centres. See Table 1 for abbreviations of EPIC cohorts

ranking of individuals according to intake is satisfactory ${ }^{15}$. A methodological study conducted at the EPIC-Potsdam study centre indicated good reproducibility of ethanol intake at age $40^{18}$, and in the EPIC dietary assessment validation studies, the capacity of the dietary assessment methods applied in EPIC to assess ethanol intake was shown ${ }^{19-29}$.

Our results are based on recalled data on alcoholic beverage consumption in the distant past - at age 20, 30 and 40 years. Previous reports of alcoholic beverage consumption and ethanol intake in the distant past were observed to be reasonably reliable and subjects were ranked consistently by repeated measures ${ }^{30-33}$. Studies investigating whether ethanol intake at baseline was similar to ethanol intake recalled for the baseline period 5-15 years later also reported reasonable reliability ${ }^{31,34-36}$ irrespective of length of recall period. Furthermore, in general, the reliability of lifetime drinking estimates ${ }^{9}$ is quite acceptable.

Caetano $^{37}$ pointed out that not only the assessment method, but also the individual characteristics of the respondent, such as age, gender, ethnicity, culture and language, may influence the estimates of alcohol consumption. Moreover, the influence of ageing on consumption is confounded by the influence of historical differences in social norms for drinking experienced by cohorts born at different points in time. This may in part explain the observation of the European Comparative Alcohol Study (ECAS) that no systematic pattern nor any common trends could be detected regarding the question of which age group drinks most at different times and in different (European) countries ${ }^{14}$. Heterogeneity of source populations in the EPIC centres ${ }^{37}$ may therefore largely explain the differences observed in the consumption of alcoholic beverages between EPIC centres. Generally, reporting could be more reliable for those EPIC study centres in countries where drinking is a socially acceptable habit and regular patterns are easier to recall than patterns with a wide variability ${ }^{37}$

The trends in alcoholic beverage consumption observed 

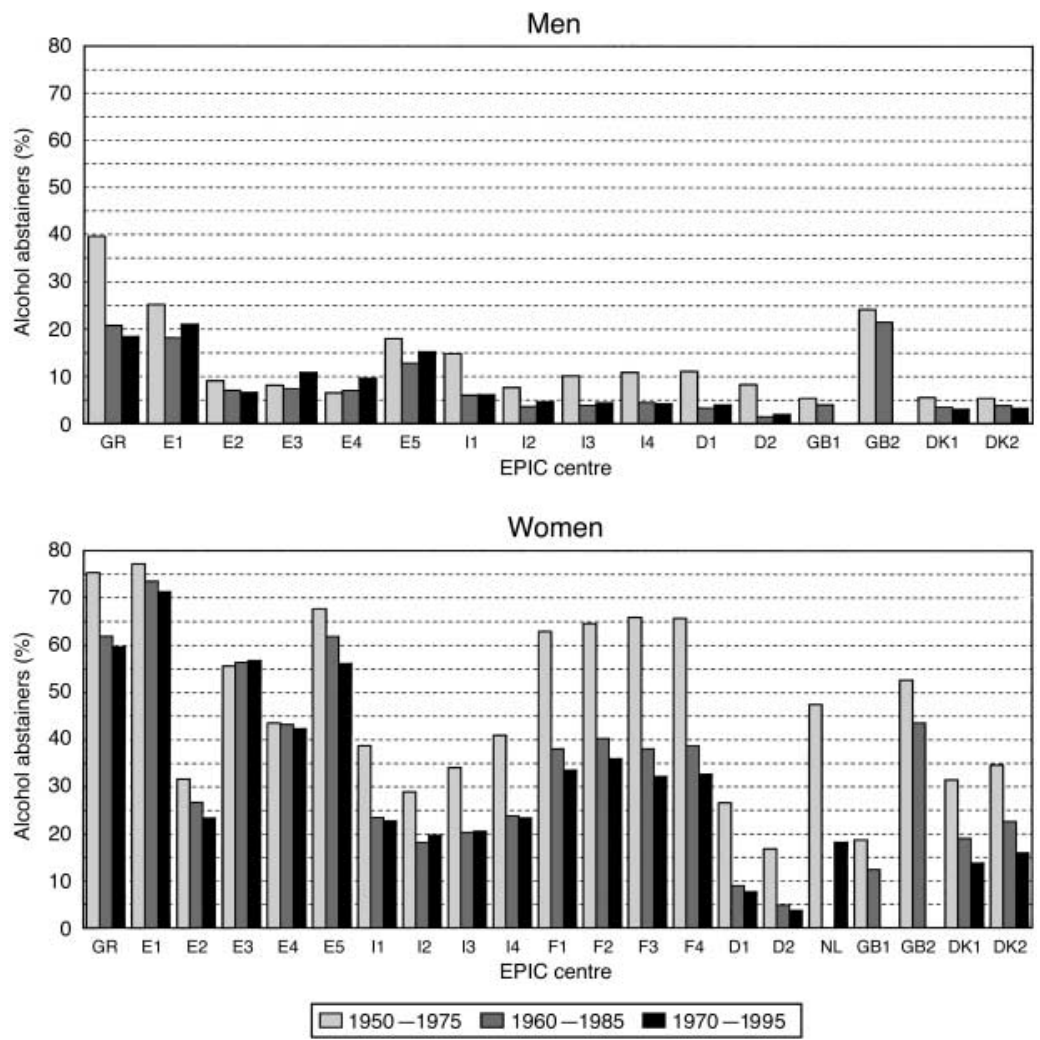

Fig. 9 Percentage of alcohol abstainers for the time periods 1950-1975, 1960-1985 and 1970-1995 for the European Prospective Investigation into Cancer and Nutrition (EPIC) study centres. See Table 1 for abbreviations of EPIC cohorts

in the current study indicate the existence of a geographical pattern with respect to wine consumption: wine consumption was observed to decrease for the time periods 1950-1975, 1960-1985 and 1970-1995 in EPIC study centres in southern Europe and to increase in EPIC study centres in northern Europe. This is in line with previous results based on analysis of per capita consumption data for Europe noting adoption of wine consumption in the north and beer consumption in the south ${ }^{38,39}$. It should be noted, however, that our results relate to the subjects within the EPIC centres and these were not intended to be representative of the respective countries. In contrast to the per capita consumption results, we observed an overall increase in beer consumption. However, discrepancies in observed trends in ethanol intake may also arise by a number of subject-specific factors determining ethanol intake and general trends on the population level - i.e. social norms with regard to alcoholic beverage consumption and the adoption of new alcoholic beverages such as fortified wines, cocktails and punches in addition to or as a substitute to traditional alcoholic beverages - as noted in a detailed analysis on current alcoholic beverage consumption within $\mathrm{EPIC}^{40}$. Indicators partly reflecting social norms with regard to ethanol intake are the male/female ratio and the distribution and percentage of alcohol abstainers in a population. Over time, a more (e.g. Heidelberg, Germany) or less (Italian study centres) marked decrease of the male/female ratio of ethanol intake was noted in the current study. The lowest ratios were observed in study centres in the UK, Denmark and also Italy. The highest ratio was seen for Spanish study centres in Asturias, Granada and Navarra, and in Greece, suggesting cultural dissimilarities between EPIC centres; i.e. that cultures might differ in the drinking norms for men and women. This notion is further supported by the observation that, for these study centres, men and women differed considerably with respect to the percentage of alcohol abstainers.

\section{Conclusion}

Trends in alcoholic beverage consumption, ethanol intake, and changes in the percentage of alcohol abstainers over time, for the time periods 1950-1975, 1960-1985 and 1970-1995, differed for both sexes and within the 21 EPIC centres. This suggests that information on past (and possibly future) alcoholic beverage consumption and ethanol intake should be included in EPIC analyses on the relationship between alcohol consumption and chronic disease.

In general, collection of information depicting lifetime history of alcoholic beverage consumption, i.e. information on ethanol intake at various discrete points in time, should be recommended in epidemiological studies on 
alcohol consumption and chronic diseases, particularly in multi-centre studies.

\section{Acknowledgements}

The work described in this paper was carried out with financial support of the 'Europe Against Cancer' Programme of the European Commission (SANCO); Ligue contre le Cancer (France); Société $3 \mathrm{M}$ (France); Mutuelle Générale de l'Education Nationale; Institut National de la Santé et de la Recherche Médicale (INSERM); Institute Gustave Roussy; German Cancer Aid; German Cancer Research Centre; German Federal Ministry of Education and Research; Danish Cancer Society; Health Research Fund (FIS) of the Spanish Ministry of Health; the Spanish Regional Governments of Andalucia, Asturias, Basque Country, Murcia and Navarra; Cancer Research UK; Medical Research Council, UK; Stroke Association, UK; British Heart Foundation; Department of Health, UK; Food Standards Agency, UK; Wellcome Trust, UK; Greek Ministry of Health; Greek Ministry of Education; Italian Association for Research on Cancer; Italian National Research Council; Dutch Ministry of Public Health, Welfare and Sports; Dutch Prevention Funds; LK Research Funds; Dutch ZON (Zorg Onderzoek Nederland); World Cancer Research Fund; Swedish Cancer Society; Swedish Scientific Council; Regional Government of Skane, Sweden; Norwegian Cancer Society; Norwegian Research Council. Partial support for the publication of this supplement was provided by the Centre de Recherche et d'Information Nutritionnelles (CERIN).

In addition, we wish to thank all study participants for their co-operation and all interviewers who participated in the fieldwork studies in each EPIC centre.

\section{References}

1 NRC Committee on Diet and Health. Diet and Health: Implications for Reducing Chronic Disease Risk. Washington, DC: National Academy Press, 1989.

2 Grobbee DE, Rimm EB, Keil U, Renaud S. Alcohol and the cardiovascular system. In: MacDonald I, ed. Health Issues Related to Alcohol Consumption. Oxford: Blackwell Science, 2000.

3 World Cancer Research Fund (WCRF)/American Institute for Cancer Research (AICR). Food, Nutrition and the Prevention of Cancer: A Global Perspective. Washington, DC: WCRF/AICR, 1997.

4 Rimm EB, Klatsky A, Grobbee D, Stampfer MJ. Review of moderate alcohol consumption and reduced risk of coronary heart disease: is the effect due to beer, wine, or spirits. $B r$. Med. J. 1996; 312: 731-6.

5 Neve RJ, Diederiks JP, Knibbe RA, Drop MJ. Developments in drinking behavior in The Netherlands from 1958 to 1989, a cohort analysis. Addiction 1993; 88: 611-21.

6 Saelan H, Moller L, Koster A. Alcohol consumption in a Danish cohort during 11 years. Scand. J. Soc. Med. 1992; 20: 87-93.

7 Kubicka L, Csemy L, Duplinsky J, Kozeny J. Czech men's drinking in changing political climates 1983-93: a threewave longitudinal study. Addiction 1998; 93: 1219-30.

8 Levenson MR, Aldwin CM, Spiro A. Age, cohort and period effects on alcohol consumption and problem drinking: findings from the Normative Aging Study. J. Stud. Alcohol. 1998; 59: 712-22.

9 Lemmens PH. Measuring lifetime drinking histories. Alcohol. Clin. Exp. Res. 1998; 22: 29S-36S.

10 Riboli E, Hunt KJ, Slimani N, Ferrari P, Norat T, Fahey M, et al. European Investigation into Cancer and Nutrition (EPIC): study populations and data collection. Public Health Nutr. 2002; 5(6B): 1113-24.

11 Riboli E, Kaaks R. The EPIC Project: rationale and study design. European Prospective Investigation into Cancer and Nutrition. Int. J. Epidemiol. 1997; 26: S6-14.

12 Slimani N, Deharveng G, Charrondière RU, van Kappel AL, Ocké MC, Welch A, et al. Structure of the standardized computerized 24-h diet recall interview used as reference method in the 22 centers participating in the EPIC project. European Prospective Investigation into Cancer and Nutrition. Comput. Meth. Programs Biomed. 1999; 58: 251-66.

13 Slimani N, Ferrari P, Ocké M, Welch A, Boeing H, van Liere $\mathrm{M}$, et al. Standardization of the 24-hour diet recall calibration method used in the European Prospective Investigation into Cancer and Nutrition (EPIC): general concepts and preliminary results. Eur. J. Clin. Nutr. 2000; 54: 900-17.

14 Midanik LT. Validity of self-reported alcohol use: a literature review and assessment. Br. J. Addict. 1988; 83: 1019-30.

15 Feunekes GI, van't Veer P, van Staveren WA, Kok FJ. Alcohol intake assessment: the sober facts. Am. J. Epidemiol. 1999; 150: $105-12$.

16 Rehm J. Measuring quantity, frequency, and volume of drinking. Alcohol. Clin. Exp. Res. 1998; 22: 4S-14S.

17 Productschap voor Gedistilleerde Dranken. World Drink Trends. Henley-on-Thames, UK: NTC Publications, 1999.

18 Klipstein-Grobusch $\mathrm{K}$, Becker $\mathrm{N}$, Kroke A, Boeing $\mathrm{H}$. Patterns of past alcohol consumption in the EPIC-Germany cohorts. European Investigation into Cancer and Nutrition. Ann. Nutr. Metab. 1999; 43: 258-65.

19 Kroke A, Klipstein-Grobusch K, Voss S, Möseneder J, Thielecke F, Noack R, et al. Validation of a self-administered food-frequency questionnaire administered in the European Prospective Investigation into Cancer and Nutrition (EPIC) study: comparison of energy, protein, and macronutrient intakes estimated with the doubly labeled water, urinary nitrogen, and repeated 24-h dietary recall methods. Am. J. Clin. Nutr. 1999; 70: 439-47.

20 Ocké MC, Bueno-de-Mesquita HB, Pols MA, Smit HA, van Staveren WA, Kromhout D. The Dutch EPIC food frequency questionnaire. II. Relative validity and reproducibility for nutrients. Int. J. Epidemiol. 1997; 26: S49-58.

21 Ocké MC, Bueno-de-Mesquita HB, Goddijn HE, et al. The Dutch EPIC food frequency questionnaire. I. Description of the questionnaire, and relative validity and reproducibility for food groups. Int. J. Epidemiol. 1997; 26: S37-48.

22 Bohlscheid-Thomas S, Hoting I, Boeing H, Wahrendorf J. Reproducibility and relative validity of energy and macronutrient intake of a food frequency questionnaire developed for the German part of the EPIC project. European Prospective Investigation into Cancer and Nutrition. Int. J. Epidemiol. 1997; 26: S71-81.

23 Bohlscheid-Thomas S, Hoting I, Boeing H, Wahrendorf J. Reproducibility and relative validity of food group intake in a food frequency questionnaire developed for the German part of the EPIC project. European Prospective Investigation into Cancer and Nutrition. Int. J. Epidemiol. 1997; 26: S59-70.

24 EPIC Group of Spain. Relative validity and reproducibility of a diet history questionnaire in Spain. I. Foods. European 
Prospective Investigation into Cancer and Nutrition. Int. J. Epidemiol. 1997; 26: S91-9.

25 EPIC Group of Spain. Relative validity and reproducibility of a diet history questionnaire in Spain. II. Nutrients. European Prospective Investigation into Cancer and Nutrition. Int. J. Epidemiol. 1997; 26: S100-9.

26 Katsouyanni K, Rimm EB, Gnardellis C, Trichopoulos D, Polychronopoulos E, Trichopoulou A. Reproducibility and relative validity of an extensive semi-quantitative food frequency questionnaire using dietary records and biochemical markers among Greek schoolteachers. Int J. Epidemiol. 1997; 26: S118-27.

27 Van Liere MJ, Lucas F, Clavel F, Slimani N, Villeminot S, Relative validity and reproducibility of a French dietary history questionnaire. Int. J. Epidemiol. 1997; 26: S128-36.

28 Pisani P, Faggiano F, Krogh V, Palli D, Vineis P, Berrino F. Relative validity and reproducibility of a food frequency dietary questionnaire for use in the Italian EPIC centres. Int J. Epidemiol. 1997; 26: S152-60.

29 Riboli E, Elmstahl S, Saracci R, Gullberg B, Lindgarde F. The Malmö Food Study: validity of two dietary assessment methods for measuring nutrient intake. Int. J. Epidemiol. 1997; 26: S161-73.

30 Giovannucci E, Colditz G, Stampfer MJ, Rimm EB, Litin L, Sampson L, et al. The assessment of alcohol consumption by a simple self-administered questionnaire. Am.J. Epidemiol. 1991; 133: 810-7.

31 Liu S, Serdula MK, Byers T, Williamson DF, Mokdad AH, Flanders WD. Reliability of alcohol intake as recalled from 10 years in the past. Am. J. Epidemiol. 1996; 143: 177-86.

32 Longnecker MP, Newcomb PA, Mittendorf R, Greenberg ER,
Clapp RW, Bogdan G, et al. The reliability of self-reported alcohol consumption in the remote past. Epidemiology 1992; 3: 535-9.

33 Lee MM, Whittemore AS, Lung DL. Reliability of recalled physical activity, cigarette smoking, and alcohol consumption. Ann. Epidemiol. 1992; 2: 705-14.

34 Czarnecki DM, Russell M, Cooper ML, Salter D. Five-year reliability of self-reported alcohol consumption. J. Stud. Alcohol. 1990; 51: 68-76.

35 Simpura J, Poikolainen K. Accuracy of retrospective measurement of individual alcohol consumption in men; a reinterview after 18 years. J. Stud. Alcohol. 1983; 44: 911-7.

36 Thompson FE, Lamphiear DE, Metzner HL, Hawthorne VM, Oh MS. Reproducibility of reports of frequency of food use in the Tecumseh Diet Methodology Study. Am.J. Epidemiol. 1987; 125: 658-71.

37 Caetano R. Cultural and subgroup issues in measuring consumption. Alcohol. Clin. Exp. Res. 1998; 22: 21S-8S

38 Hupkens CL, Knibbe RA, Drop MJ. Alcohol consumption in the European community: uniformity and diversity in drinking patterns. Addiction 1993; 88: 1391-404.

39 Norström T. Alcohol in Postwar Europe: Consumption and Drinking Patterns, Consequences and Policy Responses in 15 European Countries. Stockholm: European Commission, 2001.

40 Sieri S, Agudo A, Kesse E, Klipstein-Grobusch K, San-José B, Welch AA, et al. Patterns of alcohol consumption in 10 European countries participating in the European Prospective Investigation into Cancer and Nutrition (EPIC) project. Public Health Nutr. 2002; 5(6B): 1287-96. 